\title{
Comparative Examination of Subcutaneous Tissue Reaction to High Molecular Materials in Medical Use
}

\author{
M. Tomida ${ }^{1}$, K. Nakano ${ }^{2}$, S. Matsuura ${ }^{3}$, T. Kawakami ${ }^{2}$ \\ ${ }^{1}$ Department of Oral Physiology, Matsumoto Dental University School of Dentistry, Shiojiri, Japan \\ ${ }^{2}$ Hard Tissue Pathology Unit, Matsumoto Dental University Institute for Oral Science, Shiojiri, Japan \\ ${ }^{3}$ Department of Biology, Matsumoto Dental University School of Dentistry, Shiojiri, Japan
}

\begin{abstract}
Polypropylene (PP), Polyethylene (PE) and polytetrafluoroethylene (FE) are high molecular materials in medical use. They are also used as the negative control materials for ISO 10993-6 international standard biological evaluation of medical devices. We examined tissue reactions to these materials embedded subcutaneously in the dorsal area of male ddY mice. One week and 12 weeks after embedding, the tissue surrounding the embedding site was removed and then histopathological examination was performed. Our results demonstrate that the basic histopathological reaction is the formation of fibrous capsule consisting of granulation tissue around the embedded materials. Based on our results, we believe that the high molecular materials such as, PP, PE and FE, can be considered for medical use as a biomaterials within the body.
\end{abstract}

Key words: Tissue reaction; Histopathological evaluation; High molecular material

\section{INTRODUCTION}

Because high molecular polymer is used as a material in vivo, it should be evaluated for safety according to ISO standard 10993-6 [1, 2]. Polypropylene (PP), Polyethylene (PE) and polytetrafluoroethylene (FE) are high molecular materials in medical use, although the tissue reaction in a single material is not examined. They are also used as the negative control materials for ISO 10993-6 international standard biological evaluation of medical devices. In the present investigation, we examine the local effects after implantation of the above-mentioned materials. The data led us to believe that many researchers can know the tissue reactions to these biomaterials itself. This means next step of developing new biomaterials.

\section{Materials AND Methods}

\section{MATERIALS}

The materials to be examined include 1) Polypropylene (PP: Prime Polypro; Prime Polymer Co., Ltd., Tokyo), 2) Polyethylene (PE: HI-ZEX, Prime Polymer Co., Ltd., Tokyo) and 3) Polytetrafluoroethylene (FE: TeflonRTFE; Du Pont-Mitsui Fluorochemicals Co., Ltd., Tokyo), in discoids $6 \mathrm{~mm}$ in diameter. Materials were prepared in the following thickness: PP, $0.54 \mathrm{~mm}$;
PE, $0.79 \mathrm{~mm}$; and FE, $0.94 \mathrm{~mm}$. The materials were then disinfected by autoclave treatment.

\section{ANImALS}

A total of 18 male 9-week-old ddY mice weighing about 35g (30-40g) each were purchased from Japan SLC Inc. (Hamamatsu, Japan). The animals were kept in plastic cages with a floor mat (Paper Clean: Peparlet Co., Ltd., Shizuoka, Japan) under controlled air-conditioned room with water and solid diet (Picolab Rodent Diet 20: Japan SLC Inc., Hamamatsu, Japan) during the experimental periods.

The Matsumoto Dental University Committee for Animal Experimentation approved the study.

\section{Methods}

Prior to the examination, inhalation anesthesia was used with isoflurane (Isoflu: Dainippon Sumitomo Pharma Co., Osaka, Japan) and gas-air mixture (4.0\% concentration). Immediately after the dorsal areas of the mice were disinfected with $70 \%$ ethanol, the incisions were made, and the materials were injected subcutaneously into the connective tissues. The skin surface at the incision sites was sutured using suture string. The site was marked every 2 weeks until the final examination period at 12 weeks.

At 1 week and 12 weeks after the injection, 3 mice from each group were anaesthetized with isoflurane and gas-air mixture, and the tissues surrounding the injection sites were excised. The excised tissues were immediately fixed in $4 \%$ paraformaldehyde $/ 0.5 \mathrm{M}$ phosphate buffered solution, embedded in paraffin, and sections prepared.

The tissue sections were stained with hematoxylin and eosin and examined by light microscopy for histopathological changes. We followed the International Organization for Standardization (ISO) guidelines for evaluating the local effects of injection materials [2].

\section{RESULTS}

\section{POLYPROPYLENE: PP}

Histopathological examination of the Polypropylene group, 1-week-specimens, showed granulation tissue proliferation around the embedded material (Fig. 1, 


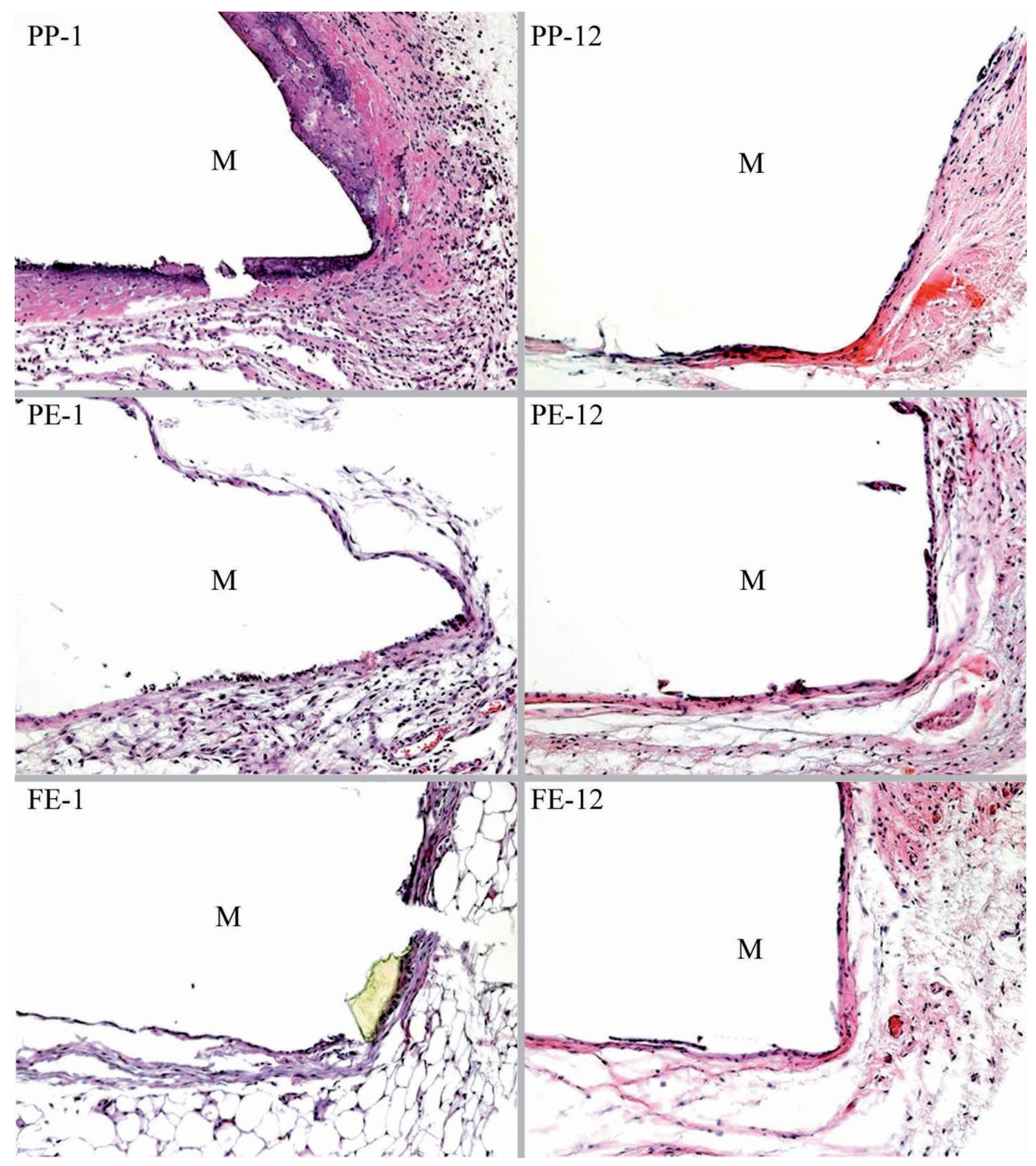

Fig. 1. PP-1: Granulation tissue formation surrounding the material PP. (PP, 1-wk-specimen, x100); PP-12: Granulation tissue with some necrotic tissue foci and inflammatory cell infiltration. (PP, 12-wk-specimen, x100); PE-1: Proliferation of scattered granulation tissue around the embedded material PE. (PE, 1-wk-specimen, x100); PE-12: The granulation tissue changed to fibrous tissue. (PE, 12-wk-specime, x100); FE-1: Thin layered fibrous capsule tissue around the material FE. (FE, 1-wk-specimen, x100); FE-12: Thin fibrous layered tissue. (FE, 12-wk-specimen, x100). M: Embedded material.

PP-1). The material attached to the surface area of the granulation tissue was stained well by eosin, showing necrotic changes. Just under the region, inflammatory cell-rich granulation tissue was observed. The enlarged view showed there were some inflammatory cells and a few fibroblasts in the surface eosin-stained region.

After 12 weeks, a thin fibrous tissue capsule tissue was formed (Fig.1, PP-12). There was almost no in- flammatory cell infiltration in the tissue; thus, the tissue began to change to fibrous tissue.

\section{Polyethylene: PE}

In 1-week specimens, proliferation of scattered granulation tissue was observed around the embedded material (Fig. 1, PE-1). In the scattered granulation tissues, 
there was some lymphocyte-rich inflammatory cell infiltration as well as capillaries showing hyperemia. The enlarged view showed that there were some eosin uniformly-stained region, which suggested necrotic change.

In 12-week specimen observations, the inflammatory cell infiltration had almost disappeared in the proliferated granulation tissues. The granulation tissues changed to fibrous tissues (Fig. 1, PE-12). Attached the surface of the determination edge of the embedded material was a thin fibrous tissue layer, which covered the scattered connective tissues. Some capillaries showing hyperemia were observed in the tissues.

\section{Polytetrafluoroethylene：FE}

In histopathological observations of 1-week specimens, we note that a thin layered fibrous capsule tissue formed around the embedded material (Fig. 1, FE-1). The fibrous capsule was slightly thick at the determination edge of the material. The thin fibrous capsule tissue had almost no inflammatory cell infiltrations.

In 12-week histopathological specimens, the fibrous tissue gradually changed to a thiner fibrous layered tissue (Fig. 1, FE-12). The enlarged view showed more clearly the state of the fibrous tissue.

\section{Discussion}

Regarding the high molecular materials, there are some published basic data on the high molecular materials in medical use, especially for use inside the body [3-7]. According to the data, their safety has been confirmed, although there are some associated inflammatory reactions [4]. We have already examined some biomaterials in this way, such as polyethylene glycol [8], squalane [9] and calcium hydroxide paste [10], according to the methods of ISO's Biological Evaluation of Medical Devices Standard [2]. For example, PE tube was applied in the ISO-testing for newly developed dental material [11].

In this paper, we evaluate three high molecular materials, PP, PE and FE, using a similar method. Among the literatures, there are some related literatures on PP, $\mathrm{PE}$ and FE [12-16]. In these published data, there are some inflammatory reactions appeared attached sites [12-16]. Therefore, the knowledge of regional tissue responses to biomaterials is useful for diagnoses of pathological conditions in clinical sites.

Our results demonstrate that the basic histopathological reaction is formation of fibrous capsule consisting of granulation tissue around the embedded materials. There were some tissue injury reactions, such as inflammatory cell infiltration. We thought the causative factor might be the low-molecular materials included in the high-molecular materials PP, PE, and FE. Furthermore, inflammatory cell infiltration, among the granulation tissue capsules of PP, was more severe compared with that of PP and FE. There were due to the additive component of PP. Furthermore, the small amount of inflammatory cell infiltration that appeared in the fibrous capsule of PE was also considered to be the same as that of PE.

In conclusion, we believe that high molecular materials such as, $\mathrm{PP}, \mathrm{PE}$ and $\mathrm{FE}$ can be considered for medical use as biomaterials within the body. As our study complied with the ISO's Biological Evaluation of Medical Devices Standard Part 12, we have appropriately evaluated the histopathological safety of using PP, PE and FE subcutaneously.

Acknowledgments: The authors thank Professor DM Carlson of Matsumoto Dental University, for his critical reading of the manuscript.

\section{REFERENCES}

1. Upman PJ: ISO 10993-6: Test for local effects after implantation. BONEZone 2006; 5(1): 50-52.

2. International Organization for Standardization (ISO): Biological Evaluation of Medical Devices -Part 1: Evaluation and testing, ISO 10993-1:2003 (E). Geneva, Switzerland. 2003.

3. Rabah DM, BeginLR, Zahran A and Corcos J. Tissue reactions of the rabit urinarybladder to cadaveric human fascia lata and polypropylene surgical mesh. Can J Urol 2004; 11: 2344-2349.

4. Esenyel CZ, Demirhan M, Kilicoglu O, Adanir O, Bilgic B, Guzel O and Ozsoy S. Evaluation of soft tissue reactions to three nonabsorbable suture materials in a rabbit model. Acta Orthop Traumatol Tuc 2009; 43: 366-372.

5. Saito T, Takemoto M, Fukuda A, Kuroda Y, Fujibayashi S, Neo M, Honjoh D, Hiraide T, Kizuki T, Kokubo T and Nakamura T. Effect of titania-based surface modification of polyethylene terephthalate on bone-implant bonding and peri-implant tissue reaction. Acta Biomatet, In Press [doi:10.1016/j.actbio.2010.11.018]

6. Bellon JM, Bujan J, Contreras LA and Jurado F. Use of nonporous polytetrafluoroethylene prosthesis in combination with polypropylene prosthetic abdominal wall implants in prevention of peritoneal abhensions. J Biomed Mater Res 1997; 38: 197-202.

7. Voskerician G, Gingras PH and Anderson JM. Macroporous condensed poly (tetrafluoroethylene). I. In vivo inflammatory response and healing characteristics. J Biomed Mater Res A 2006; 76: 234-242.

8. Kawakami T, Mizoguchi T, Matsuura S, Shimizu T, Kurihara S, Ito M and Kawai T: Histopathological safety evaluation of polyethylene glycol applied subcutaneously in mice. J Int Med Res 2004; 32: 66-69.

9. Kawakami T, Takei N, Antoh M, Hasegawa H, Kise T and Eda S. A histopathological evaluation of safety of squalane fluid applied subcutaneously. Med Sci Res 1995; 23: 521-523.

10. Shimizu T, Kawakami T, Ochiai T, Kurihara S and Hasegawa H: Histopathological evaluation of subcutaneous tissue reaction in mice to a calcium hydroxide paste developed for root canal fillings. J Int Med Res 2004; 32: 416-421.

11. Khashaba RM, Moussa MM, Chutkan NB and Borke JL: The response of subcutaneous connective tissue to newly developed calcium phosphate-based root canal sealers. Int Endod J 2011; [doi: 10.111/j.1365-2591.2010.0183 6.x.]

12. Paulo NM, Malmonge AM, Menezes LB, Lima FG, Faria AM, Andrasckho MM, Moreira NM, Atayde IB and Silva MSB: Evaluation of peritoneal adhesions formation and tissue response to polypropylene - poli (2-hydroxyethyl methacrylate)-(polyHEMA) implant on rats' abdominal wall. Acta Cirurgica Brasileira 2010; 25: 337-341.

13. Bellon JM, Gaarcia-Carranza A, Jurado F, Garcia-Honduvilla N, Carrera-San Martin A and Bujan J: Peritonneal regeneration after implant of a composite prosthesis in the abdominal wall. World J Surg; 2001; 25: 147-152. 
14. Oldinski RA, Carnson CN and James SP: Synthesis and characterization of a Hyaluronan-polyethylene copolymer for biomedical applications. J Meomed Mater Res B Appl Biomater. 2010; 94: 441-446.

15. Lee JI, Park KY and Park CH: A cluster of Teflon pledgets manifesting as an intrathoracic cavitary mass following lung resection. Thorac Cardiovas Surg 2010; 58: 250252.

16. Lin J, Chen X, Zhang W, Xu L and Zheng X: Temporal augmentation using a polytetrafluoroethylene implant with the assistance of an endoscope. Aesthetic Plast Surg 2010; 34: 701-704.
Received: February 9, 2011 / Accepted: April 13, 2011

Address for correspondence:

Toshiyuki Kawakami, PhD, Professor

Hard Tissue Pathology Unit,

Matsumoto Dental University

Graduate School of Oral Medicine,

1780 Hirooka-Gobara,

Shiojiri, 399-0781 Japan.

Phone and Fax: +81-263-51-2035

E-mail: $\quad$ kawakami@po.mdu.ac.jp 